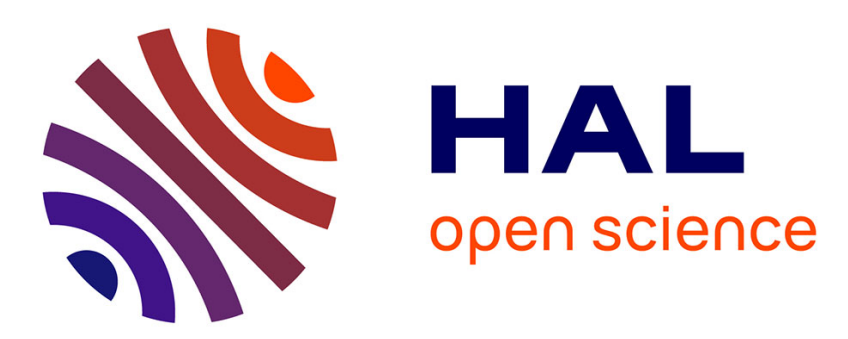

\title{
Longitudinal vibration mode of piezoelectric thick-film cantilever-based sensors in liquid media
}

\author{
Christophe Castille, Isabelle Dufour, Claude Lucat
}

\section{To cite this version:}

Christophe Castille, Isabelle Dufour, Claude Lucat. Longitudinal vibration mode of piezoelectric thick-film cantilever-based sensors in liquid media. Applied Physics Letters, 2010, 96, 154102 (3 p.). 10.1063/1.3387753 . hal-00466171

\section{HAL Id: hal-00466171 https://hal.science/hal-00466171}

Submitted on 13 Nov 2014

HAL is a multi-disciplinary open access archive for the deposit and dissemination of scientific research documents, whether they are published or not. The documents may come from teaching and research institutions in France or abroad, or from public or private research centers.
L'archive ouverte pluridisciplinaire HAL, est destinée au dépôt et à la diffusion de documents scientifiques de niveau recherche, publiés ou non, émanant des établissements d'enseignement et de recherche français ou étrangers, des laboratoires publics ou privés. 


\title{
Longitudinal vibration mode of piezoelectric thick-film cantilever-based sensors in liquid media
}

\author{
Christophe Castille, Isabelle Dufour, a) and Claude Lucat \\ Université de Bordeaux, IMS Laboratory, 351 cours de la Libération, F-33405 Talence, France
}

(Received 16 February 2010; accepted 18 March 2010; published online 14 April 2010)

\begin{abstract}
We report on the fabrication of a self-actuated resonant-microsensor, based on a thick-film piezoelectric cantilever, dedicated to either (bio)chemical detection in gaseous or liquid media or fluid characterization. The aim of this paper is to demonstrate that longitudinal modes can be used in highly viscous environments. Lower levels of fluid-solid interaction in comparison with classical flexural modes are expected from the results of our analytical model of a cantilever oscillating in a fluid. For example, in various fluid ranging from air to a Newtonian fluid of $300 \mathrm{cP}$ viscosity, measured quality factors for the first longitudinal mode range from 300 to 20. (C) 2010 American Institute of Physics. [doi:10.1063/1.3387753]
\end{abstract}

To understand the behavior of atomic force microscopy microcantilevers for physical applications or micromechanical cantilevers used for chemical sensing applications or for fluid characterization, one must understand the associated hydrodynamic phenomena. The coupling between the structure and the surrounding viscous fluid influences the characteristics of mechanical resonance; in particular, the fluid causes a decrease in quality factor and, thus, in sensing abilities. In gas, resonant frequencies of the classical transverse flexural modes may be reduced by a few percent compared with the value in vacuum, whereas $Q$ may exhibit reductions of two orders of magnitude. For the conventional flexural resonant modes, immersion in liquid results in even greater changes of the frequency response, though resonant frequencies and $Q$ values are approximately one order of magnitude smaller than their values in the gas phase. ${ }^{1}$ The reduced value of $Q$, related to the viscous losses in the surrounding medium, adversely affects the detection limit of these types of sensors. Conventionally, most silicon-based microcantilevers have been operated in the transverse bending mode. ${ }^{2}$ In that case numerical and analytic models have been developed to understand the interaction between structure and fluid in order to detect chemical species or to characterize fluid properties. ${ }^{3}$ In this letter, the use of the longitudinal (axial) mode of lead zirconate titanate (PZT) thick-film structure-based microcantilevers to obtain higher $Q$ values in liquid media is presented. Because excitation of this mode is not easy using classical silicon microcantilevers, full PZT piezoelectric microcantilevers including gold electrodes have been made with screen-printing technology. ${ }^{4}$

Screen-printed microcantilevers comprising Au/PZT/Au layers are partially released from an alumina substrate [Fig. 1(a)] using a sacrificial layer process. ${ }^{5}$ The sacrificial layer, prepared by adding strontium carbonate $\left(\mathrm{SrCO}_{3}\right)$ in an epoxy resin, is first deposited on an alumina substrate and polymerized at $120^{\circ} \mathrm{C}$. Commercial ESL (ElectroScience Laboratory) $\mathrm{Au}$ (8836) and PZT pastes are subsequently screenprinted and dried in an oven at $120{ }^{\circ} \mathrm{C}$. PZT ink is prepared from the mixture of piezoelectric Pz26 powder (Ferroperm) and 7 wt \% lead borosilicate glass-frit, blended with ESL 400

${ }^{a)}$ Electronic mail: isabelle.dufour@ims-bordeaux.fr. organic vehicle. Then, the multilayered samples are cofired $2 \mathrm{~h}$ at $850{ }^{\circ} \mathrm{C}$ in air with heating and cooling rates of $15{ }^{\circ} \mathrm{C} \mathrm{min}-1$. Finally, dissolution of the sacrificial layer is performed in a $0.9 \mathrm{~mol} \mathrm{l}^{-1} \mathrm{H}_{3} \mathrm{PO}_{4}$ aqueous solution. The fabricated piezoelectric layers $\mathrm{P}_{1}\left(10 \times 2 \times 0.075 \mathrm{~mm}^{3}\right)$, $\mathrm{P}_{2}\left(8 \times 2 \times 0.075 \mathrm{~mm}^{3}\right)$, and $\mathrm{P}_{3}\left(6 \times 1 \times 0.075 \mathrm{~mm}^{3}\right)$ are coated with 5-10 $\mu \mathrm{m}$ thick symmetrical electrodes which have slightly smaller areas than those of the piezoelectric layer [Fig. 1(b)].

For longitudinal modes, the dynamic response of a microcantilever immersed in fluid is well characterized by the following equation of motion [Fig. 1(b)]: ${ }^{6}$

$$
\rho A \frac{\partial^{2} u}{\partial t^{2}}=E A \frac{\partial^{2} u}{\partial x^{2}}-g_{1}(x, t) \frac{\partial u}{\partial t}-g_{2}(x, t) \frac{\partial^{2} u}{\partial t^{2}},
$$

where $u$ is the axial displacement (along the cantilever), $\rho$ is the mass density, $A$ is the cross-section area, $E$ is the cantilever Young modulus, and $g_{1}$ and $g_{2}$ are the fluid-dependent

(a)
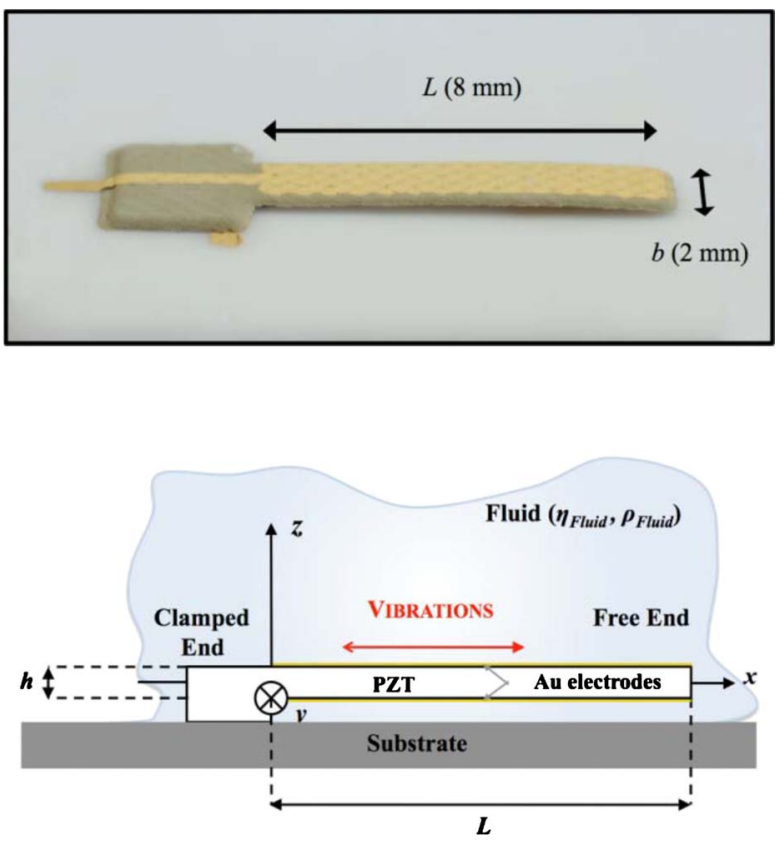

FIG. 1. (Color online) (a) Micromechanical PZT cantilever for selfactuating/sensing and (b) principle of longitudinal vibration. 
viscosity and inertia parameters for axial vibrations. The latter are well-known for the case of the conventional flexural bending modes. $^{7}$

Solution of Eq. (1) in vacuum $\left(g_{1}=g_{2}=0\right)$ gives the invacuum natural frequencies as

$$
f_{0}^{(n)}=\frac{\lambda^{(n)}}{2 \pi L} \sqrt{\frac{E}{\rho}} \quad \text { with } \lambda^{(n)}=(2 n-1) \frac{\pi}{2} ; n=1,2, \ldots .
$$

The displaced shapes (mode shapes) in vacuum at the natural frequencies are (all underlined functions are for the corresponding functions in the Fourier space)

$$
\underline{u}=l \sin \left(\lambda^{(n)} x / L\right) e^{j \omega t} .
$$

Here, $l$ characterizes the magnitude of the (small) vibration due to the piezoelectric effect, $x$ is the coordinate ranging from 0 (clamped-end) to $L$ (free-end). In fluid media, the fluid offers resistance to the motion. This resistance is composed of an inertial force, proportional to the beam acceleration, and a dissipative force, proportional to the beam velocity [respectively, $g_{2}$ and $g_{1}$ in Eq. (1)]. Thus, the cantilever dynamic response is modified by the fluid shear resistance and the resonant frequency $f_{r}^{(n)}$ (Ref. 8) may be expressed by

$$
\begin{gathered}
f_{r}^{(n)}=f_{0}^{(n)} \frac{1}{\sqrt{1+\underline{g_{2}} / \rho A}} \sqrt{1-1 / 2 Q_{\text {Fluid }}^{2}} \text { with } \\
Q_{\text {Fluid }}=\frac{2 \pi \rho A}{\underline{g_{1}}} \sqrt{1+\underline{g_{2}} \rho A} f_{0}^{(n)},
\end{gathered}
$$

where $Q_{\text {Fluid }}$ is the quality factor of the cantilever/fluid system that depends on the losses.

To clearly understand the damping effect of the fluid, the Navier-Stokes equation has been solved approximately to determine the fluid velocity around the vibrating cantilever. In particular, an analytical solution has been obtained by assuming that the fluid motion is equivalent to that corresponding to an infinite plane vibrating in-plane with a nonuniform velocity associated with the longitudinal vibration mode in vacuum [Eq. (3)]. The nonslip boundary condition at the surface $z=0$ and the motionless condition for $z=\infty$ lead to analytical expressions for each half-space $(z>0$ or $z<0,0<x$ $<L)$. Assuming that the fluid resistance on the small faces (of dimensions $h \times L$ ) is negligible compared with that due to the shear resistance of the fluid on the large faces (of dimensions $b \times L$ ), the hydrodynamic force can be determined, resulting in the following expressions for $\underline{g_{1}}$ and $\underline{g_{2}}$ :

$$
\begin{aligned}
& \underline{g_{1}}=b \sqrt{2 \sqrt{\frac{\lambda^{(n) 4} \eta_{\text {Fluid }}^{4}}{L^{4}}+4 \pi^{2} f_{r}^{(n) 2} \rho_{\text {Fluid }}^{2} \eta_{\text {Fluid }}^{2}}+2 \frac{\lambda^{(n) 2} \eta_{\text {Fluid }}^{2}}{L^{2}}}, \\
& \underline{g_{2}}=\frac{b}{2 \pi f_{r}^{(n)}} \sqrt{2 \sqrt{\frac{\lambda^{(n) 4} \eta_{\text {Fluid }}^{4}}{L^{4}}+4 \pi^{2} f_{r}^{(n) 2} \rho_{\text {Fluid }}^{2} \eta_{\text {Fluid }}^{2}}-2 \frac{\lambda^{(n) 2} \eta_{\text {Fluid }}^{2}}{L^{2}}},
\end{aligned}
$$

where $\rho_{\text {Fluid }}$ and $\eta_{\text {Fluid }}$ are the mass density and dynamic viscosity of the fluid, respectively.

Using this analytical model of the interaction between the unconventional longitudinal vibration of the cantilever and the surrounding fluid, it has been demonstrated that the use of longitudinal modes may be quite promising for (bio)chemical detection, especially in liquid, thanks to the low damping effect on the total quality factor $Q$.

Using an impedance analyzer (HP4194A), the frequency spectrum of $\mathrm{P}_{2}$ in air (Fig. 2) indicates the fundamental longitudinal piezoelectric resonance is at $f_{r}=65.7 \mathrm{kHz}$ with $Q$ $=300$. These numerical values have been confirmed with optical measurement of in-plane vibrations (MSA500 Polytec). Similar behaviors have been found for both of the other cantilevers $\left(\mathrm{P}_{1}\right.$ and $\left.\mathrm{P}_{3}\right)$ at different resonant frequencies. Making use of the piezoelectric effects, impedance measurements of the axial vibrations in various other fluids with viscosities ranging from 1.55 to $300 \mathrm{cP}$ have been performed to estimate the quality factors of the microstructures in these liquid media (Fig. 2).

Using similar measurements as presented in Fig. 2 for various cantilever geometries, the quality factors corresponding to internal losses have been determined from measurements in air: it varies from 130 for $\mathrm{P}_{3}$ to 300 for $\mathrm{P}_{1}$ and $\mathrm{P}_{2}$. Total quality factors for the three cantilever geometries have been measured to range from 70 to 107,41 to 51 , and 20 to 22 for the 1.55, 20, and $300 \mathrm{cP}$ fluids, respectively. As shown in Table I, the analytical modeling gives a good estimate of the measured quality factors and resonant frequencies.

Though the quality factor in air is relatively small because of both the electrical and mechanical losses of this

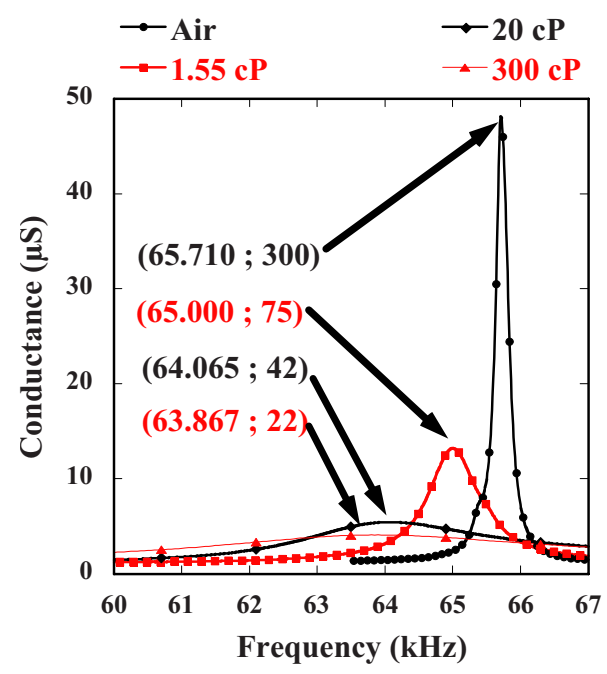

FIG. 2. (Color online) Real part of admittance (conductance) performed on $\mathrm{P}_{2}$ in various fluids (air, 1.55, 20, and $300 \mathrm{cP}$ ). 
TABLE I. Comparison between $f_{r}$ and $Q$ obtained by measurements and analytical modeling (performed on $\mathrm{P}_{2}$ ).

\begin{tabular}{cccccc}
\hline \hline & $f_{r}(\mathrm{~Hz}) ; Q$ & Air & $1.55 \mathrm{cP}$ & $20 \mathrm{cP}$ & $300 \mathrm{cP}$ \\
\hline $\mathrm{P}_{2}$ & Measurement & $65710 ; 300$ & $65000 ; 75$ & $64065 ; 42$ & $63867 ; 22$ \\
& Model & $65712 ; 308$ & $65589 ; 145$ & $65215 ; 55$ & $63747 ; 16$ \\
\hline
\end{tabular}

piezoelectric structure, the measured viscous losses are also very small as predicted with the analytical modeling.

In conclusion, the use of piezoelectric cantilevers vibrating in longitudinal modes has the potential to yield very good quality factors in liquids, even when the viscosity is large (e.g., $Q=22$ for $300 \mathrm{cP}$ ). This result is very promising for future applications in (bio)chemical detection in liquid media or fluid characterization using longitudinal modes.

This work was partially supported by the CPER Pôle $4 \mathrm{~N}$ Nanosciences en Aquitaine (GP-206-action 216/1) with the contribution of the Conseil Régional d'Aquitaine, the FEDER, and the Ministry of Education and Research, by the French National Agency (MicRheo Project No. ANR-08NANO-004) and by the Conseil Régional d'Aquitaine (Grant No. 20091102001).

${ }^{1}$ J. W. M. Chon, P. Mulvaney, and J. E. Sader, J. Appl. Phys. 87, 3978 (2000).

${ }^{2}$ K. M. Goeders, J. S. Colton, and L. A. Bottomley, Chem. Rev. 108, 522 (2008)

${ }^{3}$ N. Belmiloud, I. Dufour, A. Colin, and L. Nicu, Appl. Phys. Lett. 92, 041907 (2008).

${ }^{4}$ C. Castille, Ph.D. thesis, Université Bordeaux 1, France, March 2010.

${ }^{5}$ C. Lucat, P. Ginet, and F. Ménil, Int. J. Microelectronics and Electronics Packaging 4, 86 (2007).

${ }^{6}$ R. D. Blevins, Formulas for Natural Frequency and Mode Shape (Van Nostrand Reinhold, New York, 1979).

${ }^{7}$ A. Maali, C. Hurth, R. Boisgard, C. Jai, T. Cohen-Bouhacina, and J. P. Aimé, J. Appl. Phys. 97, 97 (2005).

${ }^{8}$ E. Sader, J. Appl. Phys. 84, 64 (1998). 